\title{
SCNS. 8. Immunohistochemical evaluation of peripheral sensory neuropathy induced by oxaliplatin in mice: involvement of microglia, glial-derived neurotrophic factor and inducible nitric oxide synthase
}

\author{
PEREIRA, A. F. ${ }^{1}$, OLIVEIRA, F. F. B. ${ }^{1}$, MOURA, C. F. ${ }^{1}$, NETO, C. ${ }^{1}{ }^{1}$, VALE, M. L ${ }^{1}$

\section{Departamento de Fisiologia e Farmacologia - Universidade Federal do Ceará}

Introduction: Oxaliplatin (OXL) is a third generation platinum compound with potent cytotoxic activity against various types of cancer, like ovary, colorectal and lung cancer. Its toxicity differs from others platinum agents, such as carboplatin and cisplatin, since it is less hematotoxic and nefrotoxic. However, a severe peripheral neuropathy stands as a side effect that complicates treatment and limits dose. Microglia has a maintenance role and has a neuroprotective effect, but these cells may also contribute to neuropathic pain processing by releasing cytokines and chemokines. The glial-derived neurotrophic factor (GDNF) is essential for nervous system survival and development and to keep its structural and functional integrity; its level rises in injured peripheral neurons and ganglia. The activity of inducible nitric oxide synthase (iNOS), the enzyme responsible for nitric oxide synthesis, rises in conditions such as tissue damage or inflammatory response. The objective of this study was to investigate microglia, GDNF and iNOS participation in peripheral neuropathy induced by oxaliplatin. Methods: The project was submitted to Ethics Commission for Animal Research (CEPA), located in Universidade Federal do Ceará (UFC), and was approved with protocol number 18/2013. Peripheral sensitive neuropathy was induced by 2 OXL injections per week (intravenous, $2 \mathrm{mg} / \mathrm{Kg})$ in Swiss male mice $(\mathrm{n}=8)$ during four weeks and half, totaling 9 injections. During this period, mice were euthanized within 24 hours, 14, 28 and 56 days after the beginning of treatment to remove dorsal root and spinal cord ganglia. Then, immunofluorescence assay was performed in order to detect lba-1 (calciumbinding adapter ionized molecule), GDNF, iNOS and NeuN on the extracted tissue in addition to quantification of the marked tissue area and morphological analysis of neurons. To verify the statistical differences between experimental groups, variance analyses (ANOVA) followed by Newman-Keuls test were used. Values of $p<0.05$ were considered statistically significant. Results: Our findings show a significant increase $(p<0.05)$ of the tissue area marked with Iba-1 in the group of mice treated for 28 days; besides, microglia showed characteristics of an activated state. Quantification of GDNF immunoexpression indicated an increase on $28^{\circ}$ day $(p<0.001)$ with evidence of GDNF release by microglia; iNOS quantification increased significantly on $14^{\circ}$ day, both in ganglia $(p<0.01)$ and spinal cord dorsal horn $(p<0.001)$. Through the marking of neurons using NeuN, suggestive alterations of apoptosis were seen on $28^{\circ}$ and $56^{\circ}$ days of treatment in the dorsal root ganglia, and in the dorsal horn of the spinal cord, on $56^{\circ}$ day of treatment. Conclusions: We concluded that the peripheral sensitive neuropathy caused by OXL involves microglial activation, increased expression of iNOS and GDNF and neuronal damage.

\section{Funding: CAPES}

PEREIRA, A. F.; OLIVEIRA, F. F. B.; MOURA, C. F.; NETO, C. S.; VALE, M. L. 2013.

Immunohistochemical evaluation of peripheral sensory neuropathy induced by oxaliplatin in mice: involvement of microglia, glial-derived neurotrophic factor and inducible nitric oxide synthase, p.19. In: Oriá, Reinaldo Barreto; Andrade, Geanne Matos de; Bruin, Veralice Meireles S. de.

I International Symposium in Neuroscience Meeting [Blucher Neuroscience Proceedings n.1 v.1]. São Paulo: Blucher, 2014, http://dx.doi.org/10.5151/isnm-sine13

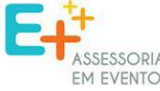

